\title{
Educating tolerance in a multicultural environment: opportunities and boundaries
}

\author{
Raisa Chumicheva ${ }^{1, *}$, Oleg Sirotkin ${ }^{2}$, and Anna Reznichenko ${ }^{1}$ \\ ${ }^{1}$ Southern Federal University, Russia \\ ${ }^{2}$ Don State Technical University, Russia
}

\begin{abstract}
The article reveals the social situations that determine the need to educate a tolerant person, which is considered as a social phenomenon; presented an analysis of approaches to the design of effective pedagogical conditions for the education of a tolerant person in the university; noted boundaries and risks in the education of a tolerant person in the multicultural educational environment of the university.
\end{abstract}

\section{Introduction}

The current situation of the development of society in a situation of self-isolation during the pandemic and especially the way out of it, when there was a new wave of economic, financial and social crisis, with the cultural and national diversity of the space of Russia, the problem of instilling tolerance in society in general and in the educational system in particular at all its levels has arisen. The analysis of the situation in society has exposed the problems that act as risks to successfully solve the problems of education in the education system, which are classified: the stratification of society on economic and social grounds; migration processes, lack of clear guidelines in their own rights; signs of intolerantness in society as hotbeds of social tension, a departure from natural tolerance in the lives of people in need of a conscious return to it; conflicts in inter-ethnic relations; rejection of a different way of life.

Today, tolerance, according to B.S. Wolfov (2002), is one of the important conditions for the formation of civil society, overcoming contradictions, displaying freedoms and equality, as well as nurturing tolerant behavior and values of tolerant consciousness [1]. The Declaration of The Principles of Tolerance was adopted by Resolution 5.61 of the UNESCO General Conference of 16, November, 1995. Article 1, p.1.1, 1.2.: "active attitude based on recognition of universal human rights and fundamental freedoms" [2]. However, tolerance, as an integral part of society and education, social legislation, has not been adequately reflected in the practical social sphere and human life and causes scientific debate in various fields of science.

Tolerance as a social phenomenon attracted the attention of thinkers and scientists of different eras and peoples. John Locke, considering the perfect tolerance, drew attention to the fact that this is a conscious recognition by the state of the freedom of the "other" and life in accordance with the law, the protection of the state of freedom of every citizen. In the statements of P. Ricker, we find that tolerance is not only a guarantee of freedoms, but also

\footnotetext{
* Corresponding author: rmchumicheva@sfedu.ru
} 
the right of the "other" in self-realization. In the understanding of P. Nicholson, J. Rolet, M. Walzer, tolerance is a personal characteristic, a moral ideal of man, a moral virtue within the theory of justice, for which peoples fought during all historical periods of society's development.

In Russian studies, we find the definition of tolerance as a moral quality of the person, virtue, a condition of successful socialization, respect for the right of another to distinction (A.A. Huseynov (2014), D.V. Sinoviev, P.F.Komogorov, A.A. Rean, V.A. Sitarov, P.F. Stepanov )[3]. In Wolfov's understanding, tolerance is a person's ability to coexist with other people with a different mentality [1]. We define tolerance as a social position of the individual, based on the values of culture and individual integrity, manifested in relation to a different culture and way of life of others, in the ability of a person to create a world of his life without violence and cruelty, to build a dialogue in any uncertain situations of life as a means of resisting violence.

At all levels of education, federal education standards define the requirements for fostering a positive attitude toward others and themselves, the ability to take into account the interests of others; to attach to sociocultural norms, traditions of the family, society, taking into account the ethnocultural situation of the development of the growing coking. The strategy of nurturing the tolerance of learners, according to scientists, can be built in several vectors:

- creation of spiritual and educational space for active participation in life, "involvement in the fullness of being by means of spiritual dialogue, awakening a deep and subtle sense of the higher laws of existence" (L.V. Surova (2011) [4];

- spiritual and moral education on the basis of cooperation, targets and meanings of human life, self-taurus of one's own behavior in situations of moral choice (M.V. Telegin (2006)) [5];

- designing the educational space as an environment for gaining morally-meaningful internal freedom and disclosure of individuality, changing the values and meanings of educating adults, displacing the rigidly determining of the life of students, the search for new educational technologies to provide a place for free initiative, freedom of knowledge and activity within culture (V.I. Slobodchikov (2010) [6].

The tasks of fostering tolerance in a comprehensive school are grouped into two blocks: the first is related to the education of tolerance towards the culture of another people, and the second - with respect for the rights and freedoms of each person.

Block 1 tasks:

Mastering and cognition of cultural values and the rules of social behavior in a multicultural environment.

Support for the culture of another people and respect for their own culture.

Education of healthy internationalism and love for Russia as a homeland or temporary place of residence.

Education of emotionally-positive attitude to representatives of other nations.

Block 2 tasks:

Education of citizenship, respect for human rights and freedoms, respect for representatives of different nationalities through the development of the rules of the "peaceful" world.

Development of the ability to understand and recognize the values of goodness, love for one's neighbor regardless of what nationality a person belongs to.

The formation of a culture of inter-ethnic relations and constructive interaction in society.

Forming ideas about the importance of human dignity, developing the skills to resolve conflicts in humane ways. 
Developing communication skills in different social situations and with different people, including with people with HIA, feelings of solidarity and the need to cooperate with them, skills to find a compromise.

Education of personal qualities - inter-ethnic tolerance, ethnocultural competence, tolerance to yourself and others, empathy and reflection.

In the process of training, future university students need to solve the following problems:

1. Introduction to the diversity of the cultural heritage of the Russian people and other peoples living not in the territory of Russia, the awareness of the value of the people in the development of the Fatherland and the service of the people;

2. Formation of multicultural competence and consciousness;

3. Developing the ability to accept people of a different cultural identity;

4. Formation of experience of prevention in the multicultural environment of conflicts in interpersonal relations (learning-learning, teacher-parent-learning, teacher-learning, teacherparent).

\section{Materials and methods}

The integration of the content of educational disciplines (foreign language, modern problems of science and education, pedagogy of inter-ethnic communication) is a consonant to solve the problems of nurturing a tolerant person in the multicultural environment of the university; technology - design, research, dialogue, IT; environments (cultural and art, cultural practices, artistic and aesthetic activities), conditioning the design of the multicultural environment of the university.

S.I. Yudakina (2011), S Nieto (2004) drew attention to the fact that the contentmeaningful content of multicultural education contributes to the inclusion of the values of world culture and successful socialization in the multi-ethnic society of the world $[7 ; 8]$. Aware of the importance of the content of education as a means of teaching and educating a tolerant person, the study was carried out through the integration of the content of educational disciplines - foreign language, modern problems of science and education, pedagogy of interethnic communication - based on the key concepts of pedagogy and psychology: values (freedom, right, respect, dignity, etc.), personality and its significant qualities (self, identical, multicultural, tolerant, with a sense of dignity and self-respect, etc.); norms, rules, etiquette and their specificity in different cultures. Ethnic and cultural differences of peoples:

- in the content of the educational discipline "foreign language" - common and different phonemes and associative series of words, etiquette and communication skills of representatives of different nationalities, etc.;

- the educational discipline "modern problems of science and education" revealed scientific concepts and theories of representatives of different peoples and currents, different points of view, discussions on the phenomenon studied;

- The "educational of inter-ethnic communication" was the final chord in the understanding of the cultural heritage of different peoples and the joint means of living in harmony in the multicultural space, ensuring the sustainability of the development of society.

K. Au (1995), P.L. Tiedt (2005) stressed that the multicultural world shapes the perception of it from the perspective of different cultures [9].

The technologies of tolerance education have become a pedagogical tool for updating the personal resource of university students in the manifestation of the qualities of a tolerant personality in the multicultural environment of the university:

-project technologies provided the organization of long-term pairing and team projects with representatives of different nationalities and educational opportunities, in which the teacher created social and problematic situations that required understanding of the other and decision-making: 
- research technologies as social team technologies of studying the problems of life in a multicultural space, requiring students to be independent in choosing partners in the study of the problem (pedagogical, social, cultural), prevention of possible conflicts on the basis of not conformity of views and points of view on the study problem or the nomination of a hypothesis;

- dialogues-reflexive, creating a discussion field of contradictory positions, points of view, judgments and opinions in the discussion of the topic of lecture or seminary, actualizing personal-significant and socially significant goals of the future teaching profession and realizing of their place in the multicultural environment;

- information and communication technologies (multimedia presentations of their cultural identity, computer simulation of life situations and means of solution: national and international content, role-playing computer games for communication in a different environment, etc.). According to D.M. Abdurazakova (2019), P. L. Tiedt's (2005) combination of dialogue and reflection techniques fosters constructive dialogue with people from different cultures, harmonizing the individual and its relationship with society [10].

The multicultural (tolerant/intolerant) environment of the university is formed spontaneously due to the influence on the educational system of social trends: the increase in the number of migrants and refugees, accessibility of the educational environment for persons with HIA, academic mobility of students, international cooperation, etc. Polyculture necessitates the creation of an educational environment of the school taking into account the cultural identity of students, which will reduce conflicts between them and ensure "harmonized coexistence of different cultures in one society" (M.A. Andrienko, N.I. Bashmakov, T.V. Poshareva, A.V. Stramnoy). N.Siniagina's (2012) multicultural environment is interpreted as a condition for the realization of a linguistic and cultural resource that ensures the formation of intercultural understanding [11]. V.P. Borisenkov (2006), O.V. Gukalenko, A.Y. Daniluk stressed the possibilities of a multicultural environment in man's place on the brink of cultures [12].

T.V. Poshtareva (2009) defined the determinants of multicultural education, in such concepts as awareness of cultural differences, a citizen of the world, capable of dialogue and solidarity, the actualization of the language of science and culture, humanistic ideas of education, integration of students in a multicultural environment [13]. The determinants specified by the author transform the educational environment, filling it with values, meanings, dialogues, art forms, etc., expanding the cultural horizons of students. A.V. Stramnoy (2020) drew attention to the following functional characteristics of the multicultural environment: value-sense context, cross-cultural communication; Regulatory function of rules and regulations; safety and learning comfort [14]. T.I. Kulikova (2017) updated the principles which define the designs of the multicultural environment and its effects: humanization, leveling of negative ethnic stereotypes, democratization of relationships, tolerance, recognition of the priority of universal values [15].

The designated determinants, functions and principles have defined the components of the multicultural environment of the university, which, in the understanding of D.M. Abdurazakova (2019), represents a socio-educational education that connects the cultural, social, educational, personal and adaptation of students in a multicultural environment [16]. The multiculturalism of the educational environment of the university is supported by the works of art of different peoples as conditions for the formation of national identity of students; cultural practices in lecture and practice classes, student festivals and forums "Folklore of the People", "National podium (national doll, national costume), "My people in music, painting, decorative and applied art); photo exhibitions "Family Album", photo essays from a different ethnic group, "National Greeting Day" and others.

Analysis of the studies revealed the factors that ensure the effectiveness of the multicultural environment in the education of tolerance of students at the university. The 
effectiveness of the multicultural environment in the education of a tolerant individual is ensured by increasing cooperation with other cultures and creating a "national kaleidoscope"; organization of mini-environments of national culture and saturation of the environment by means of culture. A.N. Shevchenko's (2019) work establishes a pattern that determines the effects of tolerance education in a multicultural environment: designing an environment on the principle of flexibility and conformity to the needs of intellectual, emotional and creative personal development [17]. In the works of S.V. Agulin (2014), E.P. Svyagintseva (2011) noted that the multicultural educational environment is an effective condition if it has pluralism, multiculturalism, multi-religiousism, multi-ethnicity; involves verbal and nonverbal contacts between the subjects of communication, enriches the native culture, provides an opportunity for the individual to reach a certain level of self-knowledge, to find his place and vocation in a multifaceted world $[18 ; 19]$. V.A. Yasvin (2001) sees the developing effect of the multicultural environment in that it provides an opportunity for self-development of subjects of the educational process in space-subject, social, psychodidactic environments [20].

In the work of E.A. Mezentsev (2015) argues the need to define the boundary of he education of tolerance, which the author defined as follows: the accuracy of understanding the terms of tolerance and tolerance, the social and political discourse of tolerance, the change in society's attitude to prohibitions, the expansion of the degrees of the permitted and the narrowing of the forbidden (taboo, sin), the absence of limits of tolerance - the way to dehumanization [21]. Scientists ask questions about possible risks in a multicultural educational environment that should be perceived as possible threats to tolerance. Risks are identified: going beyond the tolerant, established in a certain society; tolerance will increase the danger to the individual, business or country; "loss of solid ground under your feet" in the situation of recognition of the right of legitimacy of the "other"; freedom through law and tolerance as Truth, but also the denial of freedom and denial of tolerance turns into a lie. M.G. Cheltsov (2019) determines ways to overcome risks: humanization of education, definition of migration policy strategies on a legal basis, prevention of aggressiveness in society by means of mass media, development of programs and technologies to create a civil society with equal rights and responsibilities of each [22]. According to T.I. Kulikova (2017), the formation of multicultural competence will determine the development of the ability and willingness of students to communicate in a multi-ethnic and multicultural environment and to show tolerance to representatives of other nationalities [15].

\section{Results and discussion}

Expected results of the formation of tolerance of students in this study are defined as following:

- multicultural competence and upbringing of students,

- sustained interest in culture, both of one's own and another people's,

- "cultural dialogue" norms, language code ownership of representatives of different communities,

- possession of such qualities as: understanding one's worth, respecting yourself and others, owning a sense of responsibility, the need for self-fulfillment in society,

- the ability to give adequate assessments to people and events for a successful life in society, "with neighbors in the "global village"

- tolerance for a person of a different culture;

- understanding of the meaning of "the value system of interpersonal communication within an ethnic group as a universal morality". 


\section{Conclusion}

The process of nurturing tolerance, according to A. Tyaglo (2001) is carried out in the following logic: "From tolerance-patience as a forced passive reaction to the "other" through neutral perception and protection of the free activity of the "other" where it is not contrary to the law - to consciously granting the weak "other" certain advantages in selfrealization" [23]. In the context of today's global challenges and opportunities for each individual, the education of tolerance in the education system, on the one hand, is becoming a challenge to the education system because of its extremely complex formation; and on the other hand, the contradiction of the concept itself encourages scientists and practitioners to find new ways to solve this difficult task, set at all levels of education.

\section{References}

1. B. Wolfov, Extracurricular 6, 12-16 (2002)

2. Declaration of the Principles of Tolerance (United Nations Organization) http://www.un.org/ru/documents/decl_conv/declarations/toleranc.sht

3. E.M. Huseynova, Young scientist 21, 626-629 (2014)

4. L.V. Surova, Education of spiritual Development, collection of articles (Moscow, 2011)

5. M.V. Telegin, Theory and practice of dialogue education of children of early preschool and elementary school age (MGPPU, Moscow, 2006)

6. V.I. Slobodchikov, Scientific notes 3. Series Pedagogy and Psychology 2(10), 3-8 (2010)

7. S.I. Yudakina, Formation of tolerance of schoolchildren in a multicultural educational environment (Pero, Moscow, 2011)

8. S. Nieto, Affirming diversity: the sociopolitical context of multicultural education (Pearson Allyn \& Bacon, Boston, 2004)

9. K. Au, Scientists note 9(3) (1995)

10. D.M. Abdurazakova, The world of science, culture, education 6(73), 131-133 (2018)

11. N.Yu. Synyagina, Educational work at school 9, 15 - 23 (2012)

12. V.P. Borisenkov, O.V. Gukalenko, A.Y. Daniluk, Multicultural Educational Space of Russia (Pedagogy, Moscow, 2006)

13. T.V. Poshtareva, Formation of ethnocultural competence of students in a multi-ethnic educational environment. Thesis... Doctor of Educational Sciences (Stavropol, 2009)

14. A.V. Stramnoy, World of Science, Culture, Education 1(80), 152-154 (2020)

15. T.I. Kulikova, Education of schoolchildren 5, 20 - 26 (2017)

16. D.M. Abdurazakova, M.H. Bersenukayeva World of science, culture, education 2(75), 10-11 (2019)

17. A.N. Shevchenko, Humanitarian Studies 1(22), 145-147 (2019)

18. S.V. Agulin, World of Science, Culture, Education 3(46), 45-46 (2014)

19. E.P. Zvyagintseva, Psychology and pedagogy: techniques and problems 22, 123-128 (2011)

20. V.A. Yaswin, Educational Environment: From Modeling to Design (Meaning, Moscow, 
2001)

21. E.A. Mezentsev, International Research Journal 8(39), 10-12 (2015)

22. M.G. Cheltsova, Interexpo Geo-Siberia 8 (2019)

23. A. Tyaglo, Tolerance today 87 (2001) https://nsportal.ru/blog/nachalnayashkola/all/2017/11/22/tsitaty-o-tolerantnosti 